\title{
A parametric method for preliminary determination of underwater vehicles deadweight
}

\author{
Jan P. Michalski, Assoc. Prof. \\ Gdansk University of Technology \\ Polish Naval University
}

\begin{abstract}
This paper describes a method useful for determination of load carrying capacity of underwater vehicle, elaborated on the basis of investigations of series of vehicles of systematically changed geometrical dimensions. By using the set of the series of vehicles their structural mass and displacement - at a given structural material and assumed maximum permissible submersion depth - were determined, and next - approximation formulae for deadweight of vehicles were obtained. Vehicle's form may be consisted of one or a few cylindrical floats of circular cross-section, ended with caps. The floats are joined together with a space pipe frame. Acceptability of design solutions results from comparison of working stress values in float's shell plating with permissible stresses as well as critical stresses. The presented method may be useful in the preliminary stage of designing the underwater vehicles - i.e. may serve for preliminary determination of a vehicle deadweight - at its given, or determined, geometrical dimensions, maximum permissible submersion depth, as well as a selected structural material.
\end{abstract}

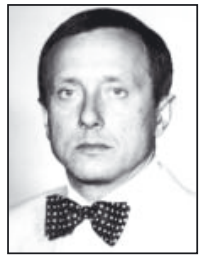

Keywords: designing of underwater vehicles; mass and deadweight of underwater vehicles

\section{INTRODUCTION}

Tight submersible vessels intended for the fulfilling of assumed functions deep in water, capable of carrying large external hydrostatic loads, find many civil and military applications such as submarines and submersible vehicles, bathyscaphes, crude-oil and gas storage tanks, or casings for measurement instruments to conduct underwater oceanological experiments.

To conduct research on phenomena occurring deep in water of seas and oceans, or in applications to offshore engineering work, are used manned and unmanned underwater vehicles capable of submersing to large depths. Such vehicles are equipped with instruments intended for: taking specimens, making measurements, navigating, filming and recording research results. In military applications the vehicles serve e.g. to place or defuse sea mines or conduct rescue operations of submarine crews. In oceanology they serve e.g. for conducting geological measurements of e.g. displacements of underwater tectonic plates, recording values of gaps, or investigating phenomena associated with underwater volcano eruptions. In the area of ocean engineering the underwater vehicles are used for exploration of ocean bed, e.g. to estimate resources of concretes laying on the bed or to inspect, maintain and repair ocean engineering devices. The designing of vehicles intended for fulfilling such functions constitutes a serious technical problem associated with the necessity of ensuring life safety to crews of vehicles as well as safety of devices and instruments against action of high hydrostatic pressure.

The set of main technical parameters of underwater vehicle, which greatly influence acceptability of design solutions, is as follows:

- maximum permissible submersion depth;

- $\quad$ kind of structural material;

- required gabarites of vehicle;

- required load-carrying capacity of vehicle;

- maximum permissible mass of vehicle;

- required speed of vertical and horizontal movements;

- zone of visibility from vessel's interior;

- maximum permissible building cost.

The set of design assumptions depends on functions and mission of a designed vehicle, and it usually contains an appropriate combination of the above mentioned technical parameters.

\section{AIM AND SCOPE OF THE WORK}

The presented work has been aimed at elaboration of a method for determining (predicting) the deadweight $\mathrm{P}_{\mathrm{N}}$ of underwater vehicles in the preliminary parametric design stage, on the basis of a few parameters of main design assumptions. 
The load carrying capacity $\mathrm{P}_{\mathrm{N}}$ is the difference of the displacement D of fully immersed vehicle and its structural mass M:

$$
\begin{gathered}
\mathrm{P}_{\mathrm{N}}\left(\mathrm{h}_{\text {min }}, \mathrm{L}, \mathrm{R}, \mathrm{H}_{\text {max }}, \mathrm{E}, \mathrm{v}\right)= \\
=\mathrm{D}(\mathrm{L}, \mathrm{R})-\mathrm{M}\left(\mathrm{h}_{\min }, \mathrm{L}, \mathrm{R}, \mathrm{H}_{\text {max }}, \mathrm{E}, \mathrm{v}\right)
\end{gathered}
$$

where:

$\mathrm{h}_{\min }-$ minimum acceptable float's plating thickness, equal to the greater of the thicknesses: $h_{c r}, h_{p e r}$ :

$$
\mathrm{h}_{\min }=\max \left(\mathrm{h}_{\mathrm{cr}}, \mathrm{h}_{\mathrm{per}}\right)
$$

$\mathrm{h}_{\mathrm{cr}}-$ critical float's plating thickness - the greatest value at which loss of stability of plating will occur under hydrostatic pressure at the depth $\mathrm{H}_{\max }$;

$\mathrm{h}_{\text {per }}-$ minimum permissible float's plating thickness - the greatest value at which permissible reduced stresses in the float's plating will be exceeded under hydrostatic pressure at the depth $\mathrm{H}_{\max }$;

$\mathrm{P}_{\mathrm{N}}-$ deadweight of vehicle;

L - length of float's cylindrical part (shell);

$\mathrm{R}$ - radius of float's shell;

$\mathrm{H}_{\max }-$ maximum permissible vehicle submersion depth;

E, v - Young modulus and Poisson ratio of structural material, respectively.

The method for preliminary determination of deadweight makes it possible to predict functional usefulness of a given design solution in the sense of estimation of value of mass which the vehicle is able to accommodate at maintaining positive buoyancy, i.e. the mass of:

- crew;

- equipment;

- instruments;

- materials;

- ballast.

The relationship (1) should serve for determination of vehicle deadweight of given dimensions, submersion depth $\mathrm{H}_{\max }$ and kind of structural material. In the case of the reverse task when a demanded deadweight is given it should serve to determine vehicle's geometrical parameters.

The applied research methodology contain the following:

choice of an interesting area of geometrical parameters of vehicles;

- a concept of geometrical configuration of vehicle;

- elaboration of systematical series of vehicles, covering the following:

- set of values of geometrical parameters of vehicles;

- set of values of permissible stresses for shell plating;

- set of values of critical pressures and stresses for shell plating;

- elaboration of approximation formulae for critical values of plating thickness;

- elaboration of approximation formulae for minimum values of plating thickness;

- elaboration of approximation formulae for values of vessel's deadweight.

The considered range of maximum submersion depths of vessel results from the necessity of fulfilling the requirement of maintaining positive displacement of vessel at assumed structural materials. Initially the maximum permissible submersion depth of $6500 \mathrm{~m}$ was assumed, that is sufficient to ensure access to about $98 \%$ surface area of world ocean bed. Until now a few manned vehicles capable of submerging to that depth, have been built [1].
The analytical approximation formulae for sets of discrete values were determined by using non-linear methods for minimizing sums of deviation squares [2].

Results of the presented research are preliminary and approximate; the parameters of the vehicles have been determined under several assumptions simplifying the considered design problem. The method may be useful for preliminary design analyses or serve for generating initial values in searching the design solutions in further design stages performed with the use of more accurate design tools e.g. computer systems for structural analysis based on finite element methods. The presented method constitutes a successive contribution to elaboration of set of preliminary design methodical tools for underwater vehicles and is continuation of the methods published in [3] and [4].

\section{GEOMETRICAL DESCRIPTION OF VEHICLE}

The assumed geometrical configuration of vehicle is consisted of the axially symmetrical floats joined together with the space frame, as shown in Fig. 1.

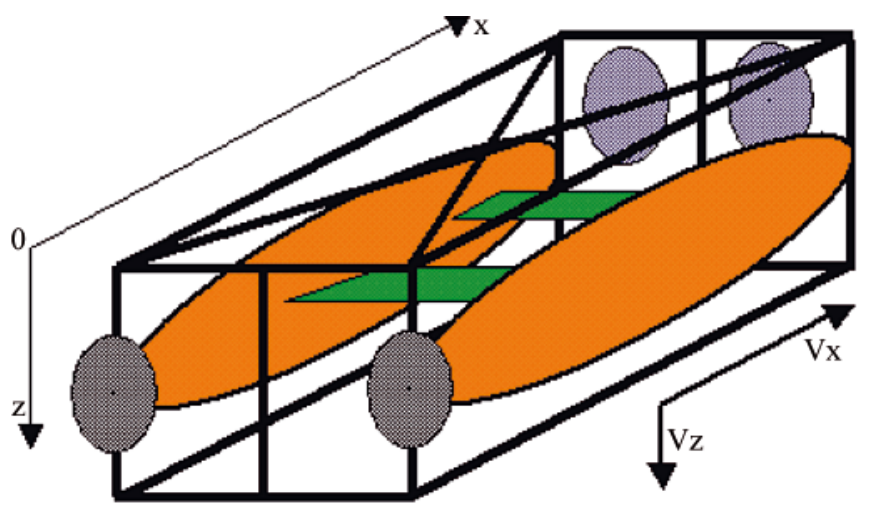

Fig. 1. Draft of simplified configuration of underwater vehicle

The vehicle's float is consisted of the shell plating (cylindrical part) and caps closing the shell. The caps support the shell loaded with constant external hydrostatic pressure. At an appropriate form of the caps the state of internal forces in float's shell plating is momentless, for instance it is the case when cap's surface is described by the generatrix of the equation as follows [5]:

$$
\zeta=\frac{\mathrm{z}}{1_{\mathrm{d}}}=\left[1-\left(\frac{\mathrm{r}}{\mathrm{R}}\right)^{2}\right]^{\frac{1}{\mathrm{t}}} \longrightarrow \mathrm{z}=1_{\mathrm{d}} \cdot\left[1-\left(\frac{\mathrm{r}}{\mathrm{R}}\right)^{2}\right]^{\frac{1}{\mathrm{t}}}
$$

where:

$t>2$ - exponent value;

$r_{d}=r / R$ - dimensionless radius of float, $0<r_{d}<1$;

$\zeta=\mathrm{z} / \mathrm{l}_{\mathrm{d}}-$ dimensionless camber of cap, $0<\zeta<1$;

$\mathrm{Z} \quad$ - cap's generatrix;

$1_{\mathrm{d}} \quad-$ cap's camber.

The total length of float $\mathrm{L}_{c}$, if length of shell is equal to $\mathrm{L}$, is as follows:

$$
\mathrm{L}_{\mathrm{c}}=\mathrm{L}+2 \mathrm{l}_{\mathrm{d}}
$$

The surface area of cap can be determined by using the formula [4]:

$$
\mathrm{S}_{\mathrm{d}}\left(\mathrm{R}, \frac{1_{\mathrm{d}}}{\mathrm{R}}, \mathrm{t}\right) \cong \pi \cdot \mathrm{R}^{2} \cdot\left[1+0.4281 \cdot\left(\frac{1_{\mathrm{d}}}{\mathrm{R}}\right)^{1.411} \cdot \mathrm{t}^{0.4862}\right]
$$

where: $\mathrm{S}_{\mathrm{d}}\left[\mathrm{m}^{2}\right]$ and $\mathrm{R}[\mathrm{m}]$. 
The cap's volume can be approximated as follows [4]:

$$
\mathrm{V}_{\mathrm{d}}\left(\mathrm{R}, \frac{1_{\mathrm{d}}}{\mathrm{R}}, \mathrm{t}\right) \cong 0.5747 \cdot \pi \cdot \frac{1_{\mathrm{d}}}{\mathrm{R}} \cdot \mathrm{t}^{0.2339} \cdot \mathrm{R}^{3}
$$

where: $\mathrm{V}_{\mathrm{d}}\left[\mathrm{m}^{3}\right]$ and $\mathrm{R}[\mathrm{m}]$.

The float's volume $\mathrm{V}$ is consisted of the volume $\mathrm{V}_{\mathrm{c}}$ of the shell of the length $\mathrm{L}$ and the cap's volumes:

$$
\mathrm{V}_{\mathrm{c}}=\pi \cdot \mathrm{R}^{2} \cdot \mathrm{L} \wedge \mathrm{V}=2 \mathrm{~V}_{\mathrm{d}}+\mathrm{V}_{\mathrm{c}}
$$

The displacement of the vehicle with $\mathrm{i}$ - floats is:

$$
\mathrm{D}=\rho \cdot \mathrm{i} \cdot \mathrm{V}
$$

\section{SAFETY CRITERIA FOR VEHICLE}

The dimensioning of shell plating thickness of float under hydrostatic pressure results from two safety criteria for float structure, namely:

- strength criterion which consists in confronting working stresses against permissible stresses in float shell plating;

- form stability criterion for float shell plating - by determining a critical pressure, exceedance of which results in loss of initial form of the shell.

The static equilibrium state of cylindrical form of float under constant external pressure at momentless state of stresses in shell plating, within the range of linear elastic deformations, is described by certain function of the form: $\mathrm{w}=\mathrm{w}(\mathrm{z}, \varphi)$, which is a solution of Eq. (9) which expresses shell plating strain energy. Depending on float's parameters, loss of stability of shell plating form may occur in the mode of axial or circumferential buckling $[5,6]$. The mode of form stability loss depends on combination of float's geometrical and material parameters and loading, which are arguments of solutions of the shell stability equations (9) and (10), which express a pressure value causing loss of form stability.

Under certain simplifying assumptions the form stability equation can be represented as follows [5]:

$$
\begin{gathered}
\mathrm{G} \cdot \nabla^{8} \mathrm{w}+\frac{\mathrm{E} \cdot \mathrm{h}}{\mathrm{R}^{2}} \cdot \frac{\partial^{4} \mathrm{w}}{\partial \mathrm{z}^{4}}+\frac{1}{2} \cdot \mathrm{p} \cdot \mathrm{R} \cdot \nabla^{4}\left(\frac{\partial^{2} \mathrm{w}}{\partial \mathrm{z}^{2}}\right)+ \\
+\mathrm{p} \cdot \mathrm{R} \cdot \nabla^{4}\left(\frac{\partial^{2} \mathrm{w}}{\mathrm{R}^{2} \cdot \partial \varphi^{2}}\right)=0
\end{gathered}
$$

where:

$$
\begin{gathered}
\nabla^{4} w=\frac{\partial^{4} w}{\partial z^{4}}+\frac{2}{R^{2}} \frac{\partial^{4} w}{\partial z^{2} \cdot \partial \varphi^{2}}+\frac{1}{R^{4}} \cdot \frac{\partial^{4} w}{\partial \varphi^{4}} \\
G=\frac{E \cdot h^{3}}{12 \cdot\left(1-v^{2}\right)}
\end{gathered}
$$

and $\mathrm{G}$ - shell stiffness in bending, and $\mathrm{h}$ - shell plating thickness.

An allowable function of an a priori assumed form, which satisfies boundary conditions for shell plating deformations may be a solution of Eq. (9), e.g. the following function:

$$
\mathrm{W}=\overline{\mathrm{w}} \cdot \sin \frac{\pi \cdot \mathrm{m} \cdot \mathrm{z}}{\mathrm{L}} \cdot \cos (\mathrm{n} \cdot \varphi)
$$

where:

$\overline{\mathrm{W}}$ - shell plating deflection;

$\mathrm{m}$ - number of longitudinal deformation half-waves;

$\mathrm{n}-$ number of circumferential deformation waves.
On substitution of the form function w into Eq. (9) the algebraic equation is obtained:

$$
\begin{gathered}
\frac{\overline{\mathrm{W}}}{\mathrm{R}^{6}}\left\{\frac{\mathrm{D}}{\mathrm{R}^{2}} \cdot\left[\left(\pi \cdot \mathrm{m} \frac{\mathrm{R}}{\mathrm{L}}\right)^{2}+\mathrm{n}^{2}\right]^{4}+\mathrm{E} \cdot \mathrm{h}\left(\pi \cdot \mathrm{m} \frac{\mathrm{R}}{\mathrm{L}}\right)^{4}+\right. \\
\left.-\mathrm{p} \cdot \mathrm{R} \cdot\left[\frac{1}{2}\left(\pi \cdot \mathrm{m} \frac{\mathrm{R}}{\mathrm{L}}\right)^{2}+\mathrm{n}^{2}\right] \cdot\left[\left(\pi \cdot \mathrm{m} \frac{\mathrm{R}}{\mathrm{L}}\right)^{2}+\mathrm{n}^{2}\right]^{2}\right\} . \\
\cdot \sin \frac{\pi \cdot \mathrm{m} \cdot \mathrm{z}}{\mathrm{L}} \cdot \cos (\mathrm{n} \cdot \varphi)=0
\end{gathered}
$$

The pressure $\mathrm{p}$ which satisfies this equation is determined by the relation as follows [5]:

$$
p(n, m)=\frac{\frac{\left(s^{2}+n^{2}\right)^{4}}{12 \cdot\left(1-v^{2}\right)}+s^{4} \cdot\left(\frac{R}{h}\right)^{2}}{\left(\frac{s^{2}}{2}+n^{2}\right) \cdot\left(s^{2}+n^{2}\right)^{2}} \cdot E \cdot\left(\frac{h}{R}\right)^{3}
$$

where: $\mathrm{s}=\pi \cdot \mathrm{m} \cdot \frac{\mathrm{R}}{\mathrm{L}}$

The critical value $p_{c r}$ at which shell plating of cylindrical float under constant external pressure loses its form stability in the range of elastic deformations (undergoes buckling), is equal to the smallest value of the expression $p(n, m)(14)$ - with respect to the number of longitudinal deformation half-waves, $\mathrm{m}$, and the number of circumferential deformation waves, $\mathrm{n}$, with which respective modes of form deformations and critical pressure correspond, at constant values of the dimension ratios $\mathrm{R} / \mathrm{L}$ and $\mathrm{R} / \mathrm{h}$ and the material constants $\mathrm{E}$ and $\mathrm{v}$, namely:

$$
\mathrm{p}_{\mathrm{cr}}=\min _{\mathrm{m}, \mathrm{n}}\{\mathrm{p}(\mathrm{m}, \mathrm{n})\}
$$

where:

$\mathrm{m} \wedge \mathrm{n} \in \mathrm{N}-$ natural number.

\section{ASSUMPTIONS USED IN THE PRESENTED METHOD}

The presented method was elaborated by assuming the typical geometrical features of uderwater vehicles and typical structural materials, which define and determine the set of parameters of the considered series of vehicles:

- the assumed number of half-waves of float axial deformations:

$\mathrm{m}=1$

- the allowable range of shell dimension ratio:

$\mathrm{R} / \mathrm{L} 0.05 \leq \mathrm{R} / \mathrm{L} \leq 0.2$

- the allowable range of the shell dimension ratio:

$\mathrm{R} / \mathrm{h} 10 \leq \mathrm{R} / \mathrm{h} \leq 25$

- the geometrical parameters of cap:

$\mathrm{t}=3, \mathrm{l}_{\mathrm{d}}=\mathrm{L}_{\mathrm{d}} / \mathrm{R}=1$

- the range of maximum submersion depth: $\operatorname{maxH}=6500 \mathrm{~m}$

- the structural material steel and alloy AL-5083

- material density of steel, AL-5083, respectively: $\rho=7.8 \mathrm{t} / \mathrm{m}^{3} \wedge \rho=2.7 \mathrm{t} / \mathrm{m}^{3}$

- Poisson ratio (of steel, AL-5083, respectively): $\mathrm{v}=0.3 \wedge \mathrm{v}=0.33$

- Young modulus of steel: $\mathrm{E}=2.1 \cdot 10^{5} \mathrm{MPa}$

- Young modulus of AL-5083: $\mathrm{E}=0.72 \cdot 10^{5} \mathrm{MPa}$. 
Under the above assumptions the series of vehicles of the following dimensions was determined:

$$
\begin{aligned}
& 0.25 \mathrm{~m}<\mathrm{R}<3.0 \mathrm{~m} \wedge 5 \mathrm{~m}<\mathrm{L}<15 \mathrm{~m} \wedge \mathrm{R} / \mathrm{L}= \\
& =\{0.05,0.1,0.2\} \wedge \mathrm{R} / \mathrm{h}=\{10,12,20,25\}
\end{aligned}
$$

\section{FORM STABILITY CRITERION FOR SHELL PLATING}

The critical pressure $p_{c r}$ is equal to the smallest pressure value which causes shell plating buckling with taking into account all possible modes of deformations $[4,5,6]$ :

$$
p_{c r}=\min _{m, n \in N} f(m, n, R / L, h / R, v, E)
$$

On the basis of the determined set of discrete critical pressure values $\left\{\mathrm{p}_{\mathrm{cr}, \mathrm{i}}\right\}$ calculated by (14) for the series of vehicles of steel shell plating the following non-structural formula which approximates the critical pressure, was determined:

$$
\begin{gathered}
\quad \mathrm{p}_{\mathrm{cr}}(\mathrm{L}, \mathrm{R}, \mathrm{h})=\mathrm{c} 1+\mathrm{c} 2 \cdot(\mathrm{R} / \mathrm{h})^{\mathrm{c} 3}+ \\
+\mathrm{c} 4 \cdot(\mathrm{R} / \mathrm{L})^{\mathrm{c} 5}+\mathrm{c} 6 \cdot(\mathrm{R} / \mathrm{h})^{\mathrm{c} 7} \cdot(\mathrm{R} / \mathrm{L})^{\mathrm{c} 8}
\end{gathered}
$$

where pressure in $[\mathrm{MPa}]$, and the formula coefficients ci are contained in Tab. 1.

Tab. 1. The coefficients ci in the formula (18) for $p_{c r}(L, R, h)$ in the case of steel shell plating of vehicle floats

\begin{tabular}{|c|c|c|c|}
\hline c1 & c2 & c3 & c4 \\
\hline-1.91 & -2994114 & -2.11949 & 0.00323536 \\
\hline $\mathbf{c 5}$ & $\mathbf{c 6}$ & $\mathbf{c 7}$ & $\mathbf{c 8}$ \\
\hline-2.59774 & 3036663 & -2.1208 & 0.0033 \\
\hline
\end{tabular}

The critical pressure for floats made of AL-5083 alloy is approximated by the following formula:

$$
p_{c r}(L, R, h)=c 1+\frac{c 2 \cdot\left(\frac{h}{R}\right)^{c 3}+c 4 \cdot\left(\frac{R}{L}\right)^{c 5}}{c 6 \cdot\left(\frac{h}{R}\right)^{c 7}+c 8 \cdot\left(\frac{R}{L}\right)^{c 9}}
$$

which expresses the best obtained approximation. The pressure is in $[\mathrm{MPa}]$, and the formula coefficients ci are contained in Tab. 2 .

Tab. 2. The coefficients $\mathrm{ci}$ in the formula (19) for $p_{c r}(L, R, h)$ in the case of AL-5083-alloy shell plating of vehicle floats

\begin{tabular}{|c|c|c|c|c|}
\hline c1 & c2 & c3 & c4 & c5 \\
\hline-0.095624 & 1267.01 & 3.5370424 & $1.84 \mathrm{E}-008$ & -5.040246 \\
\hline $\mathbf{c 6}$ & $\mathbf{c 7}$ & $\mathbf{c 8}$ & \multicolumn{2}{|c|}{$\mathbf{c 9}$} \\
\hline 0.18952 & 1.446856 & 1.92182 & \multicolumn{2}{|c|}{-2.4462} \\
\hline
\end{tabular}

In the preliminary designing procedure the reverse relation $\mathrm{h}_{\mathrm{cr}}=\mathrm{f}(\mathrm{L}, \mathrm{R}, \mathrm{H})$, which expresses the critical thickness of float's shell plating in function of the critical pressure $\mathrm{p}_{\mathrm{cr}}$, is also useful. The best obtained approximation of such relation both for steel floats and AL-5083-alloy floats is represented by the following formula:

$$
\begin{gathered}
\mathrm{h}_{\mathrm{cr}}(\mathrm{L}, \mathrm{R}, \mathrm{H})= \\
\mathrm{R}\left(\mathrm{c} 1+\mathrm{c} 2 \cdot \mathrm{H}^{\mathrm{c} 3}+\mathrm{c} 4 \cdot \mathrm{H}^{\mathrm{c} 5} \cdot(\mathrm{R} / \mathrm{L})^{\mathrm{c} 6}\right)
\end{gathered}
$$

where: shell plating thickness, float's diameter and submersion depth are expressed in [m].
Tab. 3.

In the case of steel floats the coefficients ci are given in

Tab. 3. The coefficients $\mathrm{ci}$ in the formula (20)

for $h_{c r}$ in the case of steel shell plating of floats

\begin{tabular}{|c|c|c|}
\hline c1 & c2 & c3 \\
\hline-0.073192 & 5.662381 & 0.2618387 \\
\hline $\mathbf{c 4}$ & $\mathbf{c 5}$ & $\mathbf{c 6}$ \\
\hline-5.64124 & 0.2620584 & 0.000532829 \\
\hline
\end{tabular}

In the case of AL-5083 -alloy floats the coefficients ci are given in Tab. 4.

Tab. 4. The coefficients $\mathrm{ci}$ in the formula (20) for $h_{c r}$ in the case of AL-5083 -alloy shell plating of floats

\begin{tabular}{|c|c|c|}
\hline c1 & c2 & c3 \\
\hline-0.080252 & 15.6114 & 0.2498738 \\
\hline c4 & c5 & c6 \\
\hline-15.582 & 0.24999 & 0.000273278 \\
\hline
\end{tabular}

\section{STRENGTH CRITERION FOR SHELL PLATING}

In compliance with the Mises-Huber hypothesis the effort measure of structural material is determined by the reduced stress:

$$
\sigma_{\text {red }}=\frac{1}{\sqrt{2}} \sqrt{\begin{array}{l}
\left(\sigma_{x}-\sigma_{y}\right)^{2}+\left(\sigma_{y}-\sigma_{z}\right)^{2}+ \\
+\left(\sigma_{z}-\sigma_{x}\right)^{2}+6 \cdot\left(\tau_{\mathrm{xy}}^{2}+\tau_{\mathrm{yz}}^{2}+\tau_{\mathrm{zx}}^{2}\right)
\end{array}}
$$

In the case of thin-walled shells (of $\mathrm{R} / \mathrm{h}>10$ ) and momentless loading of float, the stress state in the shell plating can be deemed planar, then the reduced stress can be expressed by means of the principal stresses: $\sigma_{z}-$ axial and $\sigma_{\varphi}$ - circumferential ones, as follows [5]:

$$
\sigma_{\text {red }}=\sqrt{\sigma_{\mathrm{z}}^{2}+\sigma_{\varphi}^{2}-\sigma_{\mathrm{z}} \cdot \sigma_{\varphi}}
$$

The strength safety criterion requires the maximum reduced stresses in shell plating not to exceed the permissible ones. Their value may be related to the yield point $R_{e}$ of structural material, and the safety factor $n_{s}>1$ of a value complying with a relevant standard or determined on the basis of experiments and practice, may be applied to obtain:

$$
\sigma_{\max }<\sigma_{\text {per }}=\mathrm{R}_{\mathrm{e}} / \mathrm{n}_{\mathrm{s}}
$$

Depending on a required reliability of a device, value of the safety factor is usually contained within the range of $n_{s}=1.1 \div 20$, but most often of $n_{s}=2.5 \div 4.0[5,6]$. Hence the formula for the strength safety criterion takes the following form:

$$
\sigma_{\text {red max }}=\max \left(\sqrt{\sigma_{\mathrm{z}}^{2}+\sigma_{\varphi}^{2}-\sigma_{\mathrm{z}} \cdot \sigma_{\varphi}}\right) \leq \sigma_{\mathrm{per}}=\frac{\mathrm{R}_{\mathrm{e}}}{\mathrm{n}_{\mathrm{s}}}
$$

In the momentless state of stresses the float shell plating is under compression of uniformly distributed axial and circumferential forces. Unitary compressive forces in float shell plating, which result from the pressure $p$, are determined by the following relations:

axial force per unit length of float circumference

$$
\mathrm{N}_{\mathrm{z}}=\frac{\mathrm{F}}{2 \cdot \pi \cdot \mathrm{R}}=\frac{\pi \cdot \mathrm{R}^{2} \cdot \mathrm{p}}{2 \cdot \pi \cdot \mathrm{R}} \cong 0.5 \cdot \mathrm{R} \cdot \mathrm{p}
$$


- circumferential force per unit length of float

$$
\mathrm{N}_{\varphi}=\frac{\mathrm{F}}{2 \cdot \mathrm{R}}=\frac{2 \cdot \mathrm{R} \cdot \mathrm{L} \cdot \mathrm{p}}{2 \cdot \mathrm{L}}=\mathrm{R} \cdot \mathrm{p}
$$

The principal axial stresses are determined by the relation:

$$
\sigma_{z}=\frac{\pi \cdot R^{2} \cdot p}{2 \cdot \pi \cdot R \cdot h} \cong 0.5 \cdot \frac{R}{h} \cdot p
$$

and, the principal circumferential stresses by:

$$
\sigma_{\varphi}=\frac{2 \cdot \mathrm{R} \cdot \mathrm{p} \cdot \mathrm{L}}{2 \cdot \mathrm{L} \cdot \mathrm{h}}=\frac{\mathrm{R}}{\mathrm{h}} \cdot \mathrm{p}
$$

At the slowly changing external pressure $p_{\max }$ exerted on float the safety stresses are determined by the relation:

$$
\begin{gathered}
\sigma_{\text {red max }}=\max \left(\sqrt{\sigma_{\mathrm{z}}^{2}+\sigma_{\varphi}^{2}-\sigma_{\mathrm{z}} \cdot \sigma_{\varphi}}\right)= \\
=\frac{\sqrt{3}}{2} \cdot \frac{\mathrm{R}}{\mathrm{h}} \cdot \mathrm{p}_{\max } \leq \sigma_{\text {per }}=\frac{\mathrm{R}_{\mathrm{e}}}{\mathrm{n}_{\mathrm{s}}}
\end{gathered}
$$

and the minimum allowable thickness of shell plating, $\mathrm{h}_{\mathrm{per}}$, is determined by the following criterion:

$$
\mathrm{h}_{\mathrm{per}} \geq \frac{\sqrt{3}}{2} \cdot \frac{\mathrm{R}}{\sigma_{\mathrm{per}}} \cdot \mathrm{p}_{\max }
$$

\section{DEADWEIGHT OF SUBMERGED VEHICLE}

By making use of the relations (2), (20), (30), the approximation formula which express the deadweight Pn of vehicle were determined, depending on:

- structural material parameters;

- the float's radius $\mathrm{R}[\mathrm{m}]$;

- the dimension ratio $\mathrm{R} / \mathrm{L}$;

- the submersion depth $\mathrm{H}$ in water of the density:

$\rho=1.025 \mathrm{t} / \mathrm{m}^{3}$.

The best obtained approximation of the deadweight, both in the case of steel shell plating and that made of AL-5083 alloy, is represented by the following expression:

$$
\begin{gathered}
\mathrm{P}_{\mathrm{N}}(\mathrm{L}, \mathrm{R}, \mathrm{H})= \\
=\mathrm{c} 1+\mathrm{c} 2 \cdot \mathrm{H}^{\mathrm{c} 3} \cdot\left(\frac{\mathrm{R}}{\mathrm{L}}\right)^{\mathrm{c} 4} \cdot \mathrm{R}^{\mathrm{c} 5}+\mathrm{c} 6 \cdot\left(\mathrm{H} \cdot \frac{\mathrm{R}}{\mathrm{L}} \cdot \mathrm{R}\right)^{\mathrm{c} 7}
\end{gathered}
$$

where the deadweight is expressed [tons], the submersion depth and float radius in [m], and the coefficients ci - in the case of steel shell plating - are contained in Tab. 5 .

Tab. 5. The coefficients $c i$ in the formula for the load carrying capacity $P_{N}$ in the case of steel shell plating of floats

\begin{tabular}{|c|c|c|c|}
\hline c1 & c2 & c3 & c4 \\
\hline 0.0176694 & 3.50444 & 0.145877 & -0.0182298 \\
\hline c5 & c6 & \multicolumn{2}{|c|}{ c7 } \\
\hline 2.129365 & -0.0019671 & \multicolumn{2}{|c|}{2.14081} \\
\hline
\end{tabular}

In the case of AL-5083 alloy shell plating the coefficients ci in the formula (31) are given in Tab. 6.

Tab. 6. The coefficients $c i$ in the formula for the load carrying capacity $P_{N}$ in the case of AL-5083-alloy shell plating of floats

\begin{tabular}{|c|c|c|c|}
\hline c1 & c2 & c3 & c4 \\
\hline 0.0554155 & 3.9192 & -0.375151 & -1.13152 \\
\hline $\mathbf{c 5}$ & c6 & \multicolumn{2}{|c|}{ c7 } \\
\hline 2.025946 & $-7.19344 \mathrm{E}-005$ & \multicolumn{2}{|c|}{1.8138323} \\
\hline
\end{tabular}

Technically acceptable are those design solutions which fulfil the condition $\mathrm{P}_{\mathrm{N}}>0$. As results from the performed research, in the case of steel floats - the formula (31) is applicable $\left(\mathrm{P}_{\mathrm{N}}>0\right)$ if both the following conditions are satisfied simultaneously:

$$
\begin{gathered}
\mathrm{H}<500 \mathrm{~m} \wedge 0.05<\mathrm{R} / \mathrm{L}<10 \wedge \\
\wedge 0.25 \mathrm{~m}<\mathrm{R}<1.50 \mathrm{~m}
\end{gathered}
$$

And, in the case of greater submersion depth values:

$$
\begin{aligned}
500 \mathrm{~m} & <\mathrm{H}<1000 \mathrm{~m} \wedge \mathrm{R} / \mathrm{L}=0.05 \wedge \\
& \wedge 0.25 \mathrm{~m}<\mathrm{R}<0.75 \mathrm{~m}
\end{aligned}
$$

In the case of AL-5083 alloy floats the formula (31) is valid, i.e. $\mathrm{P}_{\mathrm{N}}>0$, when both the following conditions are satisfied simultaneously:

$$
\begin{aligned}
500 \mathrm{~m} & <\mathrm{H}<6500 \mathrm{~m} \wedge \mathrm{R} / \mathrm{L}=0.05 \wedge \\
& \wedge 0.25 \mathrm{~m}<\mathrm{R}<0.75 \mathrm{~m}
\end{aligned}
$$

And, in the case of greater float diameter values the condition $\mathrm{P}_{\mathrm{N}}>0$ is fulfilled if both the following conditions are satisfied simultaneously:

$$
\begin{aligned}
500 \mathrm{~m} & <\mathrm{H}<1500 \mathrm{~m} \wedge \mathrm{R} / \mathrm{L}=0.10 \wedge \\
& \wedge 0.50 \mathrm{~m}<\mathrm{R}<1.50 \mathrm{~m}
\end{aligned}
$$

\section{EXAMPLES OF APPLICATION OF THE PRESENTED METHOD}

\section{Example 1.}

The design parameters have to be determined for an underwater vehicle float made of steel, having shell length $\mathrm{L}=15.00 \mathrm{~m}$, shell diameter $\mathrm{d}=1.50 \mathrm{~m}$, and cap parameters $l_{\mathrm{d}}=\mathrm{R}$ and $\mathrm{t}=3$, for the maximum permissible submersion depth $\mathrm{H}=900 \mathrm{~m}$.

For the given parameters, in accordance with Eq. (31):

the load carrying capacity of the float is:

$$
\begin{aligned}
& \mathrm{P}_{\mathrm{N}}=0.0176694+3.504440 .145877 \text {. } \\
& \cdot 0.05^{-0.0182298} \cdot 0.75^{2.129365+} \\
& -0.0019671 \cdot(900 \cdot 0.05 \cdot 0.75)^{2.14081}
\end{aligned}
$$

the mass displacement of the float, acc. (6), (7) and (8), is:

$$
\mathrm{D}=\rho \cdot \mathrm{V} \cong 1.025 \cdot 2 \text {. }
$$

$$
\cdot\left[\left(0.5747 \cdot \pi \cdot \frac{1_{d}}{R} \cdot t^{0.2339} \cdot \mathrm{R}^{3}\right)+\pi \cdot \mathrm{R}^{2} \cdot \mathrm{L}\right] \cong 29.2 \mathrm{t}
$$

the critical shell plating thickness of the float, acc. (20), is:

$$
\begin{gathered}
\mathrm{h}_{\mathrm{cr}} \cong \mathrm{R} \cdot\left(\mathrm{c} 1+\mathrm{c} 2 \cdot \mathrm{H}^{\mathrm{c} 3}+\mathrm{c} 4 \cdot \mathrm{H}^{\mathrm{c} 5} \cdot\left(\frac{\mathrm{R}}{\mathrm{L}}\right)^{\mathrm{c} 6}\right) \cong \\
\cong 0.75 \cdot\left(-0.073192+5.662381 \cdot 900^{0.261838}+\right. \\
\left.-5.64124 \cdot 900^{0.262058} \cdot(0.05)^{0.00053283}\right) \cong \\
\cong 0.0418 \mathrm{~m}=41.8 \mathrm{~mm}
\end{gathered}
$$

the reduced stresses in shell plating, based on Eq. (29), are:

$$
\begin{gathered}
\sigma_{\text {red }}=\frac{\sqrt{3}}{2} \cdot \frac{R}{h} \cdot p=\frac{\sqrt{3}}{2} \cdot \frac{0.75}{0.0418} . \\
\cdot 0.001 \cdot 900 \cdot 1.025 \cdot 9.81 \cong 141 \mathrm{Mpa}
\end{gathered}
$$




\section{Example 2.}

The design parameters have to be determined for an underwater vehicle consisted of two floats made of AL-5083 alloy and having the shell length $\mathrm{L}=15.00 \mathrm{~m}$, shell diameter $\mathrm{d}=1.50 \mathrm{~m}$ and the cap parameters $l_{\mathrm{d}}=\mathrm{R}$ and $\mathrm{t}=3$. The maximum permissible submersion depth has to be equal to $\mathrm{H}=3000 \mathrm{~m}$.

For the given parameters:

- the load carrying capacity of the float, acc. Eq.(31), is:

$\mathrm{P}_{\mathrm{N}}=2 \cdot\left(0.00554155+3.9192053000^{-0.375151}\right.$.

$$
\begin{aligned}
& \text {-0.05-1.131516 } 0.75^{2.025946-0.0000719344} \text {. } \\
& \left.\cdot(3000 \cdot 0.05 \cdot 0.75)^{1.813832}\right) \cong 5.79 \mathrm{t}
\end{aligned}
$$

- the mass displacement of the float, acc. Eq.(6), (7) and (8), is:

$$
\begin{gathered}
\mathrm{D}=\rho \cdot \mathrm{V} \cong \\
\cong 2 \cdot\left\{1.025 \cdot 2 \cdot \pi \cdot\left[\left(0.5747 \cdot \frac{1_{\mathrm{d}}}{\mathrm{R}} \cdot \mathrm{t}^{0.2339} \cdot \mathrm{R}^{3}\right)+\mathrm{R}^{2} \cdot \mathrm{L}\right]\right. \\
\cong 58.4 \mathrm{t}
\end{gathered}
$$

- the critical shell plating thickness of the float, acc. (20), is:

$$
\begin{gathered}
\mathrm{h}_{\mathrm{cr}} \cong \mathrm{R} \cdot\left(\mathrm{c} 1+\mathrm{c} 2 \cdot \mathrm{H}^{\mathrm{c} 3}+\mathrm{c} 4 \cdot \mathrm{H}^{\mathrm{c} 5} \cdot\left(\frac{\mathrm{R}}{\mathrm{L}}\right)^{\mathrm{c} 6}\right) \cong \\
\cong 0.75 \cdot\left(-0.080252+15.6114 \cdot 3000^{0.2498738}+\right. \\
\left.-15.582 \cdot 3000^{0.24999} \cdot\left(\frac{0.75}{15}\right)^{0.000273278}\right) \cong \\
\cong 0.09538 \mathrm{~m} \cong 95.4 \mathrm{~mm}
\end{gathered}
$$

- the reduced stresses in shell plating, based on Eq. (29), are:

$$
\begin{gathered}
\sigma_{\text {red }}=\frac{\sqrt{3}}{2} \cdot \frac{\mathrm{R}}{\mathrm{h}} \cdot \mathrm{p}=\frac{\sqrt{3}}{2} \cdot \frac{0.75}{0.0954} . \\
\cdot 0.001 \cdot 3000 \cdot 1.025 \cdot 9.81 \cong 205 \mathrm{Mpa}
\end{gathered}
$$

\section{NOMENCLATURE}

D - mass displacement in state of submersion;

E - Young modulus of structural material;

$\mathrm{G}$ - shell plating stiffness in bending;

$\mathrm{H}$ - submersion depth;

$\mathrm{H}_{\max }$ - maximum permissible submersion depth of vehicle;

$\mathrm{L}$ - float shell length;

$\mathrm{L}_{\mathrm{c}}$ - total float length;

$\mathrm{M}$ - mass of structure;
$\mathrm{N}_{\mathrm{z}}$ - axial force per unit length of float circumference;

$\mathrm{N}_{\varphi}$ - circumferential force per unit length of float generatrix;

$\mathrm{P}_{\mathrm{N}}$ - load carrying capacity;

$\mathrm{R}$ - float shell radius;

$\mathrm{R}_{\mathrm{e}}$ - material yield point;

$\mathrm{S}_{\mathrm{d}}-$ cap surface area;

$\mathrm{V}$ - float volume;

$\mathrm{V}_{\mathrm{c}}$ - shell volume;

$\mathrm{V}_{\mathrm{d}}$ - cap volume;

$\mathrm{h}$ - shell plating thickness;

$\mathrm{h}_{\min }-$ minimum acceptable shell plating thickness;

$\mathrm{h}_{\mathrm{cr}}-$ critical shell plating thickness of floats;

$\mathrm{h}_{\text {per }}-$ minimum permissible shell plating thickness;

$i$ - number of floats;

$1_{d}$ - cap camber;

$\mathrm{m}$ - number of longitudinal half-waves of deformation;

$\mathrm{n}$ - number of circumferential waves of deformation;

$\mathrm{n}_{\mathrm{s}}$ - safety factor;

$\mathrm{p}$ - external pressure;

$r_{d}$ - dimensionless radius of float;

$\mathrm{t}$ - index exponent of cap form;

$\overline{\mathrm{W}}$ - shell plating deflection;

$\mathrm{Z}$ - cap generatrix;

$v$ - Poisson ratio of structural material;

$\rho$ - water density;

$\sigma_{\text {red }}-$ reduced stress;

$\sigma_{\mathrm{z}}$ - principal axial stresses;

$\sigma_{\varphi}-$ principal circumferential stresses;

$\xi$ - dimensionless camber of cap.

\section{BIBLIOGRAPHY}

1. Sborshchikov I. M.: Possibilities and Problems in Using Deep Submersibles for Geology. International Journal of Offshore and Polar Engineering Vol. 6, No.4, December 1996.

2. Sherrod P.H.: Nonlinear Regression Analysis Program.

3. Michalski J.P.: Parametric method for determination of motion characteristics of underwater vehicles, applicable in preliminary designing. Polish Maritime Research. No 2 (60). 2009.

4. Michalski J.P.: Preliminary Designing Method of External Pressure Vessels for Sea Subsurface Application. Polish Maritime Research. No 2 (64) 2010.

5. Magnucki K.: Strength and optimization of thin-walled vessels (in Polish). Wydawnictwo Naukowe PWN (State Scientific Publishers). Warsaw, Poznan, 1998.

6. Timoshenko S.: Theory of Elastic Stability. McGraw-Hill Book Co., New York, 1936.

\section{CONTACT WITH THE AUTHOR}

Assoc. Prof. Jan P. Michalski

Faculty of Ocean Engineering and Ship Technology

Gdansk University of Technology Narutowicza 11/12 80-233 Gdansk, POLAND e-mail: janmi@pg.gda.pl 